\title{
Drug-related Stevens-Johnson Syndrome and Toxic Epidermal Necrolysis: A Review
}

\author{
Rohini Arora ${ }^{1} \odot$, Rajesh K Pande ${ }^{2} \odot{\text {, Shikha } \text { Panwar }^{3} \odot \text {, Vivek Gupta }}^{4} \odot$
}

\begin{abstract}
Introduction: Stevens-Johnson syndrome (SJS) and toxic epidermal necrolysis (TEN) are rare, life-threatening, allergic reactions affecting the skin and mucous membranes. SJS is considered to be a milder form with less than $10 \%$ of body surface area (BSA) involvement. We report successful management of two cases of SJS and TEN. Firstly, a case of a 24-year-old female who presented with rashes over face, chest, and upper limbs after the oral intake of ciprofloxacin and local application of moxifloxacin eye drops. She developed high-grade fever and difficulty in breathing requiring intubation and lung-protective mechanical ventilation and was treated with high-dose methylprednisolone, azithromycin, soframycin skin dressings, and topical ocular antibiotics. Secondly, another case of a 16-year-old female who developed bullous eruptions over the trunk, arms, hands, face, and sole involving $60 \%$ of BSA, after oral intake of albendazole. She was diagnosed as TEN and successfully managed with sterile silver nitrate, soframycin dressings, and antibiotics.

Key message: Stevens-Johnson syndrome (SJS) and toxic epidermal necrolysis (TEN) are life-threatening, allergic reactions affecting the skin and mucous membranes. Early identification, withdrawal of the suspected drug, and early transfer to a specialized center decrease mortality. Keywords: Albendazole, Ciprofloxacin, Moxifloxacin, Stevens-Johnson syndrome, Toxic epidermal necrolysis. Indian Journal of Critical Care Medicine (2021): 10.5005/jp-journals-10071-23826
\end{abstract}

\section{INTRODUCTION}

Stevens-Johnson syndrome (SJS) and toxic epidermal necrolysis (TEN) are both rare and life-threatening conditions caused by a hypersensitivity reaction involving the skin and the mucous membranes. SJS is a milder form of TEN with the involvement of less than $10 \%$ of body surface area (BSA), and the condition is called TEN if the affected BSA is more than $30 \%$. The involvement of 10 to $30 \%$ of BSA is considered to be SJS-TEN. ${ }^{1}$ We report two cases - SJS by fluoroquinolones and TEN caused by albendazole. TEN caused by albendazole to the best of our knowledge has not been reported previously.

\section{Case Descriptions}

\section{Case 1}

A 24-year-old female developed erythematous rashes over the face, chest, and upper limbs after the oral intake of ciprofloxacin and local application of moxifloxacin eye drops. The patient presented with high-grade fever and breathing difficulty necessitating endotracheal intubation and ventilation. She was put on pressure control mode with lung-protective strategy. Skin involvement was found to be approximately $10 \%$ of BSA with extensive damage to the conjunctiva and symblepharon formation. A diagnosis of fluoroquinolone-induced SJS was made based on the clinical findings.

The patient was given high-dose methylprednisolone for 3 days and azithromycin. The erosions were covered with a sterile paraffin gauge and mometasone cream. The patient developed hospital-acquired pneumonia and sepsis, which were treated with appropriate antimicrobial therapy. Supportive treatment included sedatives, analgesics, and intravenous fluids. The patient improved significantly by day 10 and was weaned from the ventilator and shifted to ward on day 15 .

The patient developed symblepharon, which was released successfully. She later developed painful deglutition due to

\footnotetext{
${ }^{1-3}$ Department of Critical Care, D BL Kapur Superspeciality Hospital, New Delhi, India

${ }^{4}$ Department of Pharmacology, D BL Kapur Superspeciality Hospital, New Delhi, India

Corresponding Author: Rohini Arora, Department of Critical Care, D BL Kapur Superspeciality Hospital, New Delhi, India, Phone: +91 8588806634; e-mail: drrohini8@gmail.com

How to cite this article: Arora R, Pande RK, Panwar S, Gupta V. Drug-related Stevens-Johnson Syndrome and Toxic Epidermal Necrolysis: A Review. Indian J Crit Care Med 2021;25(5):575-579.

Source of support: Nil

Conflict of interest: None
}

glossitis and oral ulcers that was treated with local glycerin application.

\section{Case 2}

A 16-year-old female presented with bullous eruptions over her face, trunk, arms, hands, genitals, and sole covering about $60 \%$ of BSA, following oral intake of albendazole (Figs. 1 to 3). A diagnosis of TEN was established based on purplish lesions over the trunk, which were more than $30 \%$. She had tachycardia that was managed with fentanyl infusion. The patient was managed with crystalloid and albumin infusion given through the central line, early enteral feeding with a high protein diet, appropriate antibiotics, and methylprednisolone. She developed sepsis early requiring escalation of antibiotics and withdrawal of steroids. Wound care was provided with soframycin dressings (Fig. 4). and wet dressing of silver nitrate that maintains a moist wound environment. Eyes cared for with saline-soaked pads. The skin lesions improved by day 20 after which they got converted to hyperpigmented scars, and the patient was discharged home. 


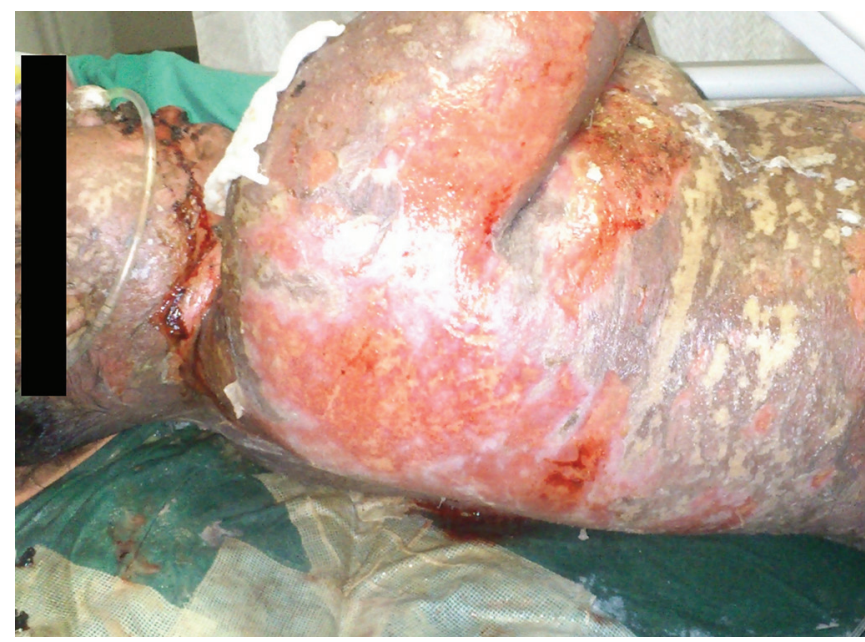

Fig. 1: Initial skin lesions involving trunk and face (Case 2)

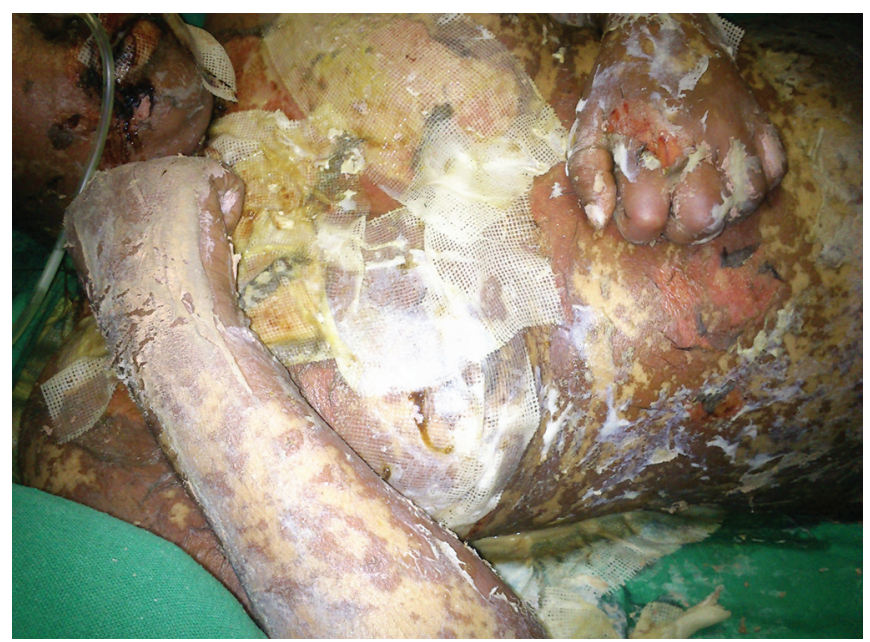

Fig. 2: Initial skin lesions over chest and abdomen (Case 2)

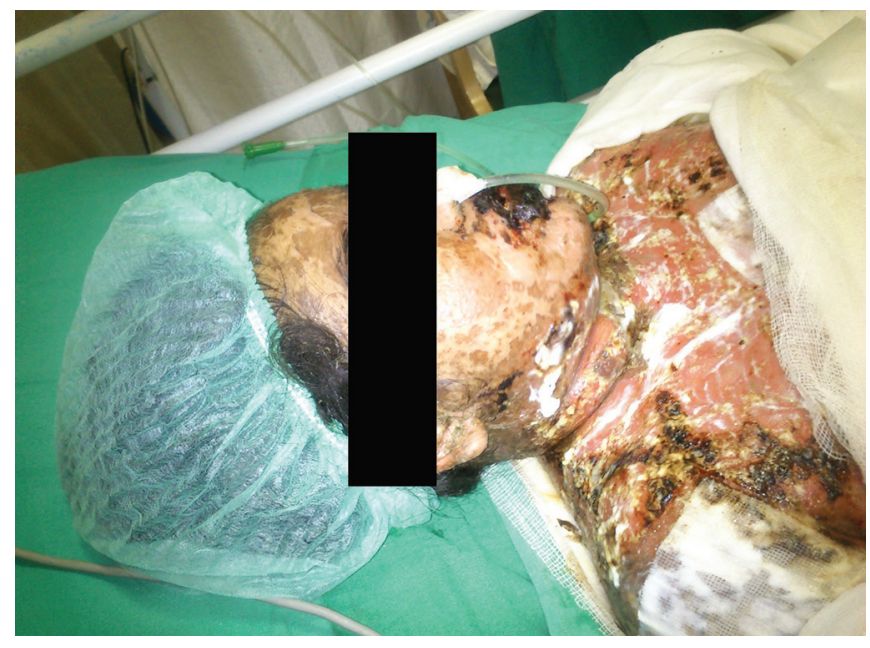

Fig. 3: Crusting (Case 2)

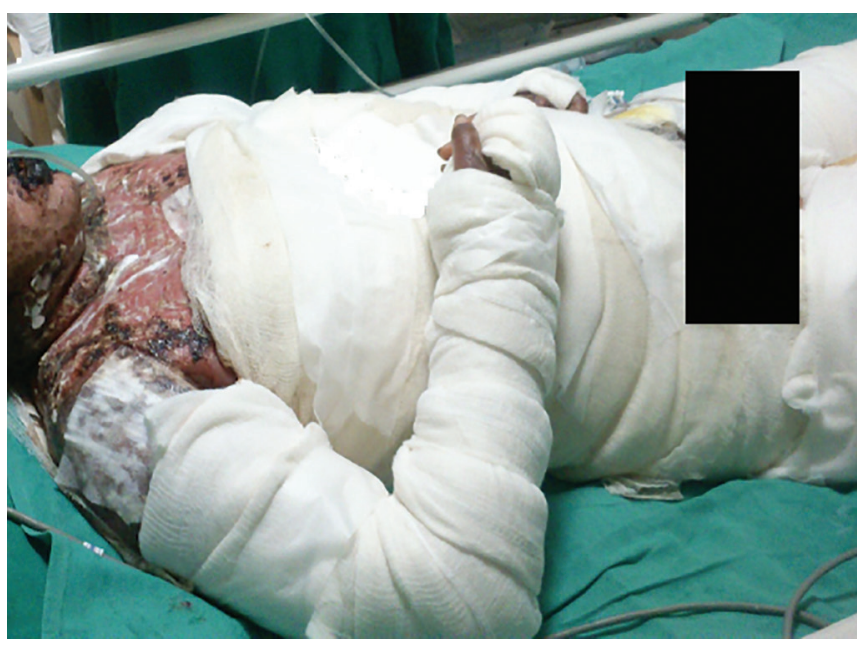

Fig. 4: Wound care and use of barrier precautions (Case 2)

\section{Discussion}

Both SJS and TEN are rare, life-threatening acute allergic drug reactions affecting the skin and mucous membranes. SJS affects less than $10 \%$ of BSA, while TEN involves more than $30 \%$ of BSA, and between 10 and $30 \%$ is SJS/TEN overlap. The mortality rate of TEN can be up to three times higher than that of SJS because of the extensive skin involvement and secondary complications. ${ }^{2}$

Drug reactions are the most common cause of SJS/TEN. Drugs like antibacterial, allopurinol, sulfonamides, anticonvulsants, and steroids are found to be associated with an increased risk of SJS/TEN. ${ }^{3}$ Among these drugs, sulfonamides, penicillin, and anticonvulsants are the commonest implicating agents for SJS/ TEN. ${ }^{4,5}$

Among nondrug infectious causes, mycoplasma pneumonia in adults and herpes simplex virus infections in children are known to cause SJS/TEN. ${ }^{6,7} \mathrm{~A}$ rare occurrence of TEN in a patient with severe aplastic anemia after allogeneic hematopoietic stem cell transplantation has also been reported. ${ }^{8}$ Lastly, vaccination is also implicated as an inciting factors like human papillomavirus, mumps, measles, rubella, hepatitis $B$, influenza, anthrax, and tetanus vaccines. ${ }^{9}$

The primary cause for the development of TEN is massive T-lymphocyte-mediated immune reaction causing destruction of the keratinocytes-expressing foreign antigens. An increased amount of inflammatory cytokines like tumor necrosis factor- $\alpha$ (TNF- $\alpha$ ) and interleukin-6 (IL-6) are found in blister fluid. ${ }^{10}$ They recruit the cytotoxic T-cells to the epidermis causing cell death by inducing apoptosis. A cascade of intracellular enzymes called caspases is activated when cytotoxic T-lymphocytes come in contact with target cells.

The patient may present with a prodromal phase of fever, malaise, cough, stinging eyes, and sore throat. Other symptoms include erythematous rash, bullae, and separation of large sheets of epidermis from the dermis. Cutaneous lesions include diffuse erythema with target-like lesions, blisters, and erosions. "Target lesions"11 are less than $3 \mathrm{~cm}$ in diameter, round, and have three concentric zones; a central area of dusky erythema, a middle paler zone of edema, and an outer ring of erythema with a defined edge. Target lesions plus involvement of at least two mucous membranes comprise SJS. 
The condition can be associated with multi-organ failure, sepsis, gastrointestinal hemorrhage, and pulmonary embolism. Ocular involvement ${ }^{12}$ of TEN occurs in $50 \%$ to $88 \%$ of cases and includes a purulent form of conjunctivitis, corneal ulceration, anterior uveitis, entropion, dry eye syndrome, and severe visual loss. ${ }^{13,14}$

Pulmonary involvement is common but usually mild in nature, ${ }^{15}$ and only 10 to $20 \%$ requires ventilator support. ${ }^{16}$ Our first case had pulmonary involvement and developed hospital- acquired pneumonia. Reported pulmonary complications include tracheobronchial mucosal necrosis, pulmonary edema, acute respiratory distress syndrome, and pneumonia in $20-50 \%$ of cases. Erosive and ulcerative vaginitis and vulvar bullae are seen in genital involvement.

\section{Long-term Sequelae Complications}

Long-term complications include xerophthalmia, ectropion, entropion, symblepharon, corneal opacity, pannus formation, nasolacrimal duct obstruction, punctal stenosis, vaginal synechiae, ${ }^{17}$ obliterative bronchitis or bronchiolitis, bronchiectasis, esophageal stricture, recurrent cystitis, lingual ulcerations, recurrent oral aphthae, etc. $^{18}$

The presence of extensive necrolysis, idiopathic nature of diseases, old age, elevated urea, creatinine and glucose levels, neutropenia, lymphopenia, and thrombocytopenia are linked to a bad prognosis. SCORTEN scale ${ }^{19}$ (Table 1) has been validated to determine the mortality rate and is considered to be the gold standard for prognosis. Our first patient had a SCORTEN score of 1 , corresponding to a reported mortality of 3.2\%. Our second patient had SCORTEN score of 3, with a reported mortality of 35.3\%. Drug provocation tests ${ }^{20}$ (DPTs) are often needed when evaluating these patients for the correct causative agent and for the preparation of a list of drugs to be given to these patients. Since DPT may itself cause reactions, it has to be done under proper medical supervision.

Table 1A: Scorten scale

\begin{tabular}{lll}
\hline Risk factor & 0 & 1 \\
\hline Age & $<40$ years & $>40$ years \\
Associated malignancy & No & Yes \\
Heart rate (beats/min) & $<120$ & $>120$ \\
Serum BUN (mg/dL) & $<27$ & $>27$ \\
Detached or compromised body & $<10 \%$ & $>10 \%$ \\
surface & $>20$ & $<20$ \\
Serum bicarbonate $(\mathrm{mEq} / \mathrm{L})$ & $<250$ & $>250$ \\
Serum glucose $(\mathrm{mg} / \mathrm{dL})$ & &
\end{tabular}

Table 1B: Percentage of mortality

\begin{tabular}{lc}
\hline No of risk factors & Mortality rate (\%) \\
\hline $0-1$ & 3.2 \\
2 & 12.1 \\
3 & 35.3 \\
4 & 58.3 \\
5 or more & $>90$ \\
\hline
\end{tabular}

\section{Management}

TEN behaves like a superficial dermal burn with fluid shifts, hypermetabolism, and high nutritional requirements. The initial aim is the prevention of secondary infection by good wound care as this is the most common cause of death. ${ }^{21}$ Early diagnosis, early withdrawal of the suspected drug, ${ }^{22}$ and early transfer and management of these patients in a specialized unit like intensive care or burn unit ${ }^{23}$ are associated with survival benefit. ${ }^{24}$

Wound management with nonadhesive wet silver nitrate dressings maintains a moist wound environment, speeds re-epithelialization, minimizes the pain, and decreases infection rates. ${ }^{25}$ Wounds should be treated conservatively as much as possible, ${ }^{26}$ as blistered skin acts as a natural biological dressing and favors re-epithelialization. Biological or biosynthetic temporary skin replacements ${ }^{27}$ (e.g., porcine xenografts), Biobrane (skin substitute), and Aquacel Ag (a moisture-retentive hydrofiber dressing that releases silver within the dressing) are the latest modalities of skincare. Umbilical cord mesenchymal stem cell transplantation ${ }^{28}$ is an attractive and promising tool for skin regeneration in patients with severe denudation due to their self-renewal capacity, multilineage differentiation potential, paracrine effects, and immunosuppressive properties.

Pain control is a very important part of the management of SJS/TEN, as these patients experience low-intensity background pain. Longer-acting opioids and paracetamol should be given for pain.

It is important to encourage oral feeds to avoid adhesions in the upper gastrointestinal tract, but parenteral feeding may be considered when the nutritional requirement cannot be met with oral intake.

SJS/TEN patients have impaired temperature control due to loss of the integument and should be cared for in rooms with temperature and humidity control. Careful monitoring of fluid balance with strict input and output chart is essential because of significant insensible fluid losses, resulting in dehydration and renal impairment.

Eye care includes 1- to 2-hourly eye lubrication and early involvement of an ophthalmologist. Nonhealing corneal ulcers may be treated with bandage contact lenses and amniotic membrane transplantation for severe persistent corneal damage. ${ }^{29}$

\section{Specific Management}

The use of corticosteroids is debatable and remains controversial. Corticosteroids have an antiapoptotic role in the skin tissue, inhibit the initiating pathways, ${ }^{30}$ and down-regulate fas ligand (FasL) in the apoptotic tissue. Studies support the early use of high-dose corticosteroids ${ }^{30}$ (1-2 mg/kg/day of prednisolone for 3-5 days).

Dexamethasone 8 to $16 \mathrm{mg} /$ day is recommended; ${ }^{31}$ however, the dose can be increased by $4 \mathrm{mg}$ the next day if considered necessary and the recovery is not adequate. On the other hand, the opponents to corticosteroids suggest an increased risk of sepsis, prolonged hospital stay, and increased mortality. ${ }^{32}$

Other reported medical therapies for the treatment of TEN include plasmapheresis, intravenous immunoglobulins (IVIG), and cyclosporine. Literature supports early use of IVIG, ${ }^{33}$ which is a safe therapy even for children with severe cutaneous drug reactions. ${ }^{34}$ However, there are conflicting reports as well. ${ }^{35}$

Cyclosporine if given early in the disease arrests the progression of the disease without increasing the risk of sepsis. ${ }^{36}$ The mean 
duration of re-epithelialization and duration of hospital stay were significantly lower in patients receiving cyclosporine in comparison to those patients who were managed using supportive treatment only, without increasing mortality. ${ }^{37,38}$

Plasmapheresis therapy ${ }^{39}$ to remove drug metabolites and cytokines from circulation remains controversial.

Although beneficial effect of cyclophosphamide ${ }^{40}$ and tacrolimus $^{41}$ is suggested by some authors, larger studies are needed to clarify these results.

Other treatments that have been tried include chimeric antiTNF- $\alpha$ antibody (infliximab) ${ }^{42,43}$ and thalidomide (TNF-alpha inhibitor) as cytokines such as IL- 6 and TNF-alpha are found in higher quantities in the skin of patients of TEN. Recombinant granulocyte colonystimulating factor in a dose of $5 \mu \mathrm{g} / \mathrm{kg} /$ day for 5 days leads to rapid re-epithelialization of skin as reported in some case reports. But still their use remains controversial, and more robust data are required to make these treatments as a standard of care.

There are still gaps in our understanding of the pathophysiology of SJS/TEN and the available treatment options. Good quality multicenter studies are needed to understand the disease better and explore the treatment options further.

\section{Conclusion}

Life-threatening SJS and TEN present a challenge in early detection and subsequent management. Evidence-based practice related to the care of patients with SJS is still evolving. Management includes early identification, withdrawal of the suspected drug, and early transfer to a specialized center. Further research and clinical evidence are needed to develop appropriate and cost-effective treatment guidelines for optimal care of these patients.

\section{OrCID}

Rajesh K Pande 이 https://orcid.org/0000-0002-0149-727X

Rohini Arora (1) https://orcid.org/0000-0003-3322-4185

Shikha Panwar (1) https://orcid.org/0000-0002-0669-4731

Vivek Gupta @ https://orcid.org/0000-0002-8719-5677

\section{References}

1. Bastuji-Garin S, Rzany B, Stern RS, Shear NH, Naldi L, Roujeau JC. Clinical classification of cases of toxic epidermal necrolysis, Stevens- Johnson syndrome and erythema multiforme. Arch Dermatol 1993;129(1):92-96. DOI: 10.1001/archderme.

2. Barvaliya M, Sanmukhani J, Patel T, Paliwal N, Shah H, Tripathi C. Druginduced Stevens-Johnson syndrome (SJS), toxic epidermal necrolysis (TEN), and SJS-TEN overlap: a multicentric retrospective study. J Postgrad Med 2011;57(2):115-119. DOI: 10.4103/0022-3859.81865.

3. Roujeau JC, Kelly JP, Naldi L, Rzany B, Stern RS, Anderson T, et al. Medication use and the risk of Stevens-Johnson syndrome or toxic epidermal necrolysis. N Engl J Med 1995;333(24):1600-1607. DOI: 10.1056/NEJM199512143332404.

4. Sethuraman G, Sharma VK, Pahwa P, Khetan P. Causative drugs and clinical outcome in Stevens Johnson Syndrome (SJS), Toxic Epidermal Necrolysis (TEN), and SJS-TEN overlap in children. Indian J Dermatol 2012;57(3):199-200. DOI: 10.4103/0019-5154.96192.

5. Mockenhaupt M, Viboud C, Dunant A, Naldi L, Halevy S, Bouwes Bavinck JN, et al. Stevens-Johnson syndrome and toxic epidermal necrolysis: assessment of medication risks with emphasis on recently marketed drugs. The EuroSCAR-study. J Invest Dermatol 2008;128(1):35-44. DOI: 10.1038/sj.jid.5701033.

6. Mulvey JM, Padowitz A, Lindley-Jones M, Nickels R. Mycoplasma pneumoniae associated with Stevens Johnson syndrome. Anaesth Intensive Care 2007;35(3):414-417. DOI: 10.1177/0310057X0703500317.
7. Forman R, Koren G, Shear NH. Erythema multiforme, StevensJohnson syndrome and toxic epidermal necrolysis in children: a review of 10 years' experience. Drug Saf 2002;25(13):965-972. DOI: 10.2165/00002018-200225130-00006.

8. Zakrzewski JL, Lentini G, Such U, Duerr A, Tran V, Guenzelmann S, et al. Toxic epidermal necrolysis: differential diagnosis of an epidermolytic dermopathy in a hematopoietic stem cell transplant recipient. Bone Marrow Transplant 2002;30(5):331-333. DOI: 10.1038/sj.bmt.1703624.

9. Katoulis AC, Liakou A, Bozi E, Theodorakis M, Alevizou A, Zafeiraki $A$, et al. Erythema multiforme following vaccination for human papillomavirus. Dermatology 2010;220(1):60-62. DOI: $10.1159 / 000254898$.

10. Abe R. Immunological response in Stevens-Johnson syndrome and toxic epidermal necrolysis. J Dermatol 2015;42(1):42-48. DOI: $10.1111 / 1346-8138.12674$.

11. Teraki Y, Shibuya M, Izaki S. Stevens-Johnson syndrome and toxic epidermal necrolysis due to anticonvulsants share certain clinical and laboratory features with drug-induced hypersensitivity syndrome, despite differences in cutaneous presentations. Clin Exp Dermatol 2010;35(7):723-728. DOI: 10.1111/j.1365-2230.2009.03718.x.

12. López-García JS, Rivas Jara L, García-Lozano Cl, Conesa E, de Juan IE, Murube del Castillo J. Ocular features and histopathologic changes during follow-up of toxic epidermal necrolysis. Ophthalmology 2011;118(2):265-271. DOI: 10.1016/j.ophtha.2010.06.035.

13. Sotozono C, Ueta M, Koizumi N, Inatomi T, Shirakata Y, Ikezawa Z, et al. Diagnosis and treatment of Stevens-Johnson syndrome and toxic epidermal necrolysis with ocular complications. Ophthalmology 2009;116(4):685-690. DOI: 10.1016/j.ophtha.2008.12.048.

14. Gueudry J, Roujeau JC, Binaghi M, Soubrane G, Muraine M. Risk factors for the development of ocular complications of Stevens- Johnson syndrome and toxic epidermal necrolysis. Arch Dermatol 2009;145(2):157-162. DOI: 10.1001/archdermatol.2009.540.

15. Hwang SH, Kim DH, Kim JH, Son BK, Lim DH. Chronic pulmonary complications due to toxic epidermal necrolysis. Allergy Asthma Respir Dis 2013;1(4):391-394. DOI: 10.4168/aard.2013.1.4.391.

16. Kamada N, Kinoshita K, Togawa Y, Kobayashi T, Matsubara H, Kohno $M$, et al. Chronic pulmonary complications associated with toxic epidermal necrolysis: report of a severe case with anti-Ro/SS-A and a review of the published work. J Dermatol 2006;33(9):616-622. DOI: $10.1111 / j .1346-8138.2006 .00142 . x$.

17. Kaser DJ, Reichman DE, Laufer MR. Prevention of vulvovaginal sequelae in Stevens-Johnson syndrome and toxic epidermal necrolysis. Rev Obstet Gynecol 2011;4(2):81-85. DOI: 10.3909/ riog0152.

18. Oplatek A, Brown K, Sen S, Halerz M, Supple K, Gamelli RL. Long-term follow-up of patients treated for toxic epidermal necrolysis. J Burn Care Res 2006;27(1):26-33. DOI: 10.1097/01.bcr.0000194268.01514.f8.

19. Guégan S, Bastuji-Garin S, Poszepczynska-Guigné E, Roujeau JC, Revuz J. Performance of the SCORTEN during the first 5 days of hospitalization to predict the prognosis of epidermal necrolysis. J Invest Dermatol 2006;126(2):272-276. DOI: 10.1038/sj.jid.5700068.

20. Ramam M, Kumar U, Bhat R, Sharma VK. Oral drug provocation test to generate a list of safe drugs: experience with 100 patients. Indian J Dermatol Venereol Leprol 2012;78(5):595-598. DOI: 10.4103/03786323.100563.

21. Roujeau JC, Chosidow O, Saiag P, Guillaume JC. Toxic epidermal necrolysis (Lyell syndrome). J Am Acad Dermatol 1990;23(6 Pt 1):1039_ 1058. DOI: 10.1016/0190-9622(90)70333-d.

22. Garcia-Doval I, LeCleach L, Bocquet H, Otero XL, Roujeau JC. Toxic epidermal necrolysis and Stevens-Johnson syndrome: does early withdrawal of causative drugs decrease the risk of death? Arch Dermatol 2000;136(3):323-327. DOI: 10.1001/archderm.136.3.323.

23. McGee T, Munster A. Toxic epidermal necrolysis syndrome: mortality rate reduced with early referral to regional burn center. Plast Reconstr Surg 1998;102(4):1018-1022. DOI: 10.1097/00006534-19980904000014.

24. Palmieri TL, Greenhalgh DG, Saffle JR, Spence RJ, Peck MD, Jeng JC, et al. A multicenter review of toxic epidermal necrolysis treated in 
U.S. burn centers at the end of the twentieth century. J Burn Care Rehabil 2002;23(2):87-96. DOI: 10.1097/00004630-200203000-00004.

25. Worswick S, Cotliar J. Stevens-Johnson syndrome and toxic epidermal necrolysis: a review of treatment options. Dermatol Ther 2011;24(2):207-218. DOI: 10.1111/j.1529-8019.2011.01396.x.

26. Harr T, French LE. Toxic epidermal necrolysis and Stevens-Johnson syndrome. Orphanet J Rare Dis 2010;5:39. DOI: 10.1186/1750-11725- 39.

27. Ramakrishnan KM, Sankar J, Venkatraman J. Role of biological membranes in the management of Stevens Johnson syndrome Indian experience. Burns 2007;33(1):109-111. DOI: 10.1016/j. burns.2006.04.029.

28. Li X, Wang D, Lu Z, Chen J, Zhang H, Sun L. Umbilical cord mesenchymal stem cell transplantation in drug-induced StevensJohnson syndrome. J Eur Acad Dermatol Venereol 2013;27(5):659661. DOI: 10.1111/j.1468-3083.2012.04572.x.

29. Sharma N, Thenarasun SA, Kaur M, Pushker N, Khanna N, Agarwal T, et al. Adjuvant role of amniotic membrane transplantation in acute ocular Stevens-Johnson syndrome: a randomized control trial. Ophthalmology 2016;123(3):484-491. DOI: 10.1016/j.ophtha.2015.10.027.

30. O'Donoghue JM, Céspedes YP, Rockley PF, Nigra TP. Skin biopsies to assess response to systemic corticosteroid therapy in early-stage TEN case report and review of the literature. Cutis 2009;84(3):138-140.

31. Kardaun SH, Jonkman MF. Dexamethasone pulse therapy for StevensJohnson syndrome/toxic epidermal necrolysis. Acta Derm Venereol 2007;87(2):144-148. DOI: 10.2340/00015555-0214.

32. Hynes AY, Kafkala C, Daoud YJ, Foster CS. Controversy in the use of high-dose systemic steroids in the acute care of patients with Stevens-Johnson syndrome. Int Ophthalmol Clin 2005;45(4):25-48. DOI: 10.1097/01.iio.0000177430.89645.6d.

33. Prins C, Kerdel FA, Padilla RS, Hunziker T, Chimenti S, Viard I, et al. Treatment of toxic epidermal necrolysis with high dose intravenous immunoglobulins: multicenter retrospective analysis of 48 consecutive cases. Arch Dermatol 2003;139(1):26-32. DOI: 10.1001/archderm.139.1.26.

34. Barron SJ, Del Vecchio MT, Aronoff SC. Intravenous immunoglobulin in the treatment of Stevens-Johnson syndrome and toxic epidermal necrolysis: a meta-analysis with meta-regression of observational studies. Int J Dermatol 2015;54(1):108-115. DOI: 10.1111/ijd.12423.

35. Bachot N, Revuz J, Roujeau JC. Intravenous immunoglobulin treatment for Stevens-Johnson syndrome and toxic epidermal necrolysis: a prospective noncomparative study showing no benefit on mortality or progression. Arch Dermatol 2003;139(1):33-36. DOI: 10.1001/archderm.139.1.33.

36. Chave TA, Mortimer NJ, Sladden MJ, Hall AP, Hutchinson PE. Toxic epidermal necrolysis: current evidence, practical management and future directions. Br J Dermatol 2005;153(2):241253. DOI: 10.1111/j.1365-2133.2005.06721.x.

37. Singh GK, Chatterjee M, Verma R. Cyclosporine in Stevens Johnson syndrome and toxic epidermal necrolysis and retrospective comparison with systemic corticosteroid. Indian J Dermatol Venereol Leprol 2013;79(5):686-692. DOI: 10.4103/0378-6323.116738.

38. Kirchhof MG, Miliszewski MA, Sikora S, Papp A, Dutz JP. Retrospective review of Stevens-Johnson syndrome/toxic epidermal necrolysis treatment comparing intravenous immunoglobulin with cyclosporine. J Am Acad Dermatol 2014;71(5):941-947. DOI: 10.1016/ j.jaad.2014.07.016.

39. Giudice G, Maggio G, Bufano L, Memeo G, Vestita M. Management of toxic epidermal necrolysis with plasmapheresis and cyclosporine A: our 10 years' experience. Plast Reconstr Surg Glob Open 2017;5(2):e1221. DOI: 10.1097/GOX.0000000000001221.

40. Heng MC, Allen SG. Efficacy of cyclophosphamide in toxic epidermal necrolysis. Clinical and pathophysiologic aspects. J Am Acad Dermatol 1991;25(5 Pt 1):778-786. DOI: 10.1016/s01909622(08)80969-3.

41. Dogra PM, Chatterjee M, Neema S. Tacrolimus for treatment of toxic epidermal necrolysis. Indian J Dermatol Venereol Leprol 2015;81(6):642-644. DOI: 10.4103/0378-6323.168328.

42. Hunger RE, Hunziker T, Buettiker U, Braathen LR, Yawalkar N. Rapid resolution of toxic epidermal necrolysis with anti-TNF-alpha treatment. J Allergy Clin Immunol 2005;116(4):923-924. DOI: 10.1016/ j.jaci.2005.06.029.

43. Meiss F, Helmbold P, Meykadeh N, Gaber G, Marsch WCh, Fischer M. Overlap of acute generalized exanthematous pustulosis and toxic epidermal necrolysis: response to antitumour necrosis factor-alpha antibody infliximab: report of three cases. J Eur Acad Dermatol Venereol 2007;21(5):717-719. DOI: 10.1111/j.14683083.2006.02026.x.

44. Egan CA, Grant WJ, Morris SE, Saffle JR, Zone JJ. Plasmapheresis as an adjunct treatment in toxic epidermal necrolysis. J Am Acad Dermatol 1999;40(3):458-461. DOI: 10.1016/s0190-9622(99)70497-4.

45. Furubacke A, Berlin G, Anderson C, Sjöberg F. Lack of significant treatment effect of plasma exchange in the treatment of drug-induced toxic epidermal necrolysis? Intensive Care Med 1999;25(11):1307-1310. DOI: 10.1007/s001340051063.

46. Su SC, Chung WH. Cytotoxic proteins and therapeutic targets in severe cutaneous adverse reactions. Toxins (Basel) 2014;6(1):194-210. DOI: 10.3390/toxins6010194.

47. Thong BY. Stevens-Johnson syndrome/toxic epidermal necrolysis: an Asia-Pacific perspective. Asia Pac Allergy 2013;3(4):215-223. DOI: 10.5415/apallergy.2013.3.4.215. 